\title{
Adoption of conservation agriculture in the Mexican Bajío
}

\author{
Goedele Van den Broeck ${ }^{\mathrm{a}}$, Ricardo Romero Perez Grovas ${ }^{\mathrm{a}, \mathrm{c}}$, Miet Maertens ${ }^{\mathrm{a}}$, Jozef Deckers ${ }^{\mathrm{b}}$, \\ Nele Verhulst ${ }^{\mathrm{c}}$ and Bram Govaerts ${ }^{\mathrm{c}^{*}}$ \\ a Division of Bioeconomics, Department of Earth and Environmental Sciences, KU Leuven, Celestijnenlaan \\ 200E, 3001 Leuven, Belgium \\ ${ }^{b}$ Division of Soil and Water Management, Department of Earth and Environmental Sciences, KU Leuven, \\ Celestijnenlaan 200E, 3001 Leuven, Belgium \\ ${ }^{c}$ International Maize and Wheat Improvement Centre (CIMMYT), Apdo. Postal 6-641, 06600 Mexico, D.F., \\ Mexico \\ *Corresponding author: b.govaerts@cgiar.org
}

This paper was published in Outlook on Agriculture: Van den Broeck, G., Perez Grovas, R.R., Maertens, M., Deckers, J., Verhulst, N., Govaerts, B., 2013. Adoption of conservation agriculture in the Mexican Bajío. Outlook on Agriculture 42 (3), 171-178.

The final publication is available at http://www.ingentaconnect.com/content/ip/ooa

\begin{abstract}
Despite demonstrated environmental and economic benefits, the adoption of conservation agriculture (CA) often remains lower than expected. Adoption of a complex and composite technology such as CA requires a thorough understanding of site-specific determinants of and constraints in the adoption process. In this paper, we investigate the adoption of CA among medium-scale farmers in the Mexican Bajío using farm survey data. We differentiate between full and partial adoption of composite technology, and disentangle the different steps in the adoption process, including awareness, using Heckman selection models. The results indicate that institutional factors and farmers' education affect awareness of CA but not adoption itself. Farm size is not an important determinant in the adoption process but farmers' tenancy position does affect both awareness and adoption. A main constraint for full but not for partial adoption is livestock ownership, which complicates residue retention on the field, as crop residues are baled for fodder.
\end{abstract}

Keywords: conservation agriculture; technology adoption; Heckman selection model; Mexico.

\section{Introduction}

Conservation agriculture (CA) is proposed as a strategy to provide stable and high yields while conserving and even improving the quality of the natural resource base (Dumanski et al, 2006). CA is a composite agricultural technology that comprises three main principles, (i) reduced tillage ${ }^{1}$, (ii) permanent soil cover, and (iii) crop rotation (Hobbs et al, 2008; Verhulst et al, 2010). These management principles are potentially applicable to different agro-ecological zones and in a wide variety of farming systems; from rain-fed to irrigated production, and from small-scale to large-scale farming (Sayre and Hobbs, 2003; Govaerts et al, 2005). However, CA is not a clear-cut recipe and should always be adapted to local conditions, such as soil type, climate and socio-economic settings (Erenstein et al, 2008).

CA has significant environmental and economic benefits, such as improved soil water content, reduced soil erosion, and reduced labour and capital requirements. These benefits have been

\footnotetext{
${ }^{1}$ We specify reduced tillage as zero-tillage and minimal tillage.
} 
empirically validated by numerous studies conducted globally, for example, in North-America (Malhi et al, 2006), Latin America (Fabrizzi et al, 2005; Cavalieri et al, 2009), Asia (Affholder et al, 2010, Lestrelin et al, 2012), Africa (Marongwe et al, 2011; Tesfaye et al, 2011) and Europe (Lahmar, 2010). Yet, adoption rates by farmers are often not as high as expected. Various constraints might exist in the different steps in the adoption process (Derpsch et al, 2010). First, CA requires new farming skills of which farmers might not be aware. Access to information likely plays a key role in increasing the awareness of a technology and hence in successful adoption. Yet, institutional settings are often weak in developing countries, complicating the dissemination of correct information to farmers. Secondly, farmers need to be convinced of the benefits of a technology in order to adopt it on their own fields. Farmers are often described as being conservative and rather reluctant to change farming practices. In addition, they might encounter different constraints while implementing CA. For example, it might be difficult to sufficiently retain crop residues on fields due to livestock pressure (Giller et al, 2009) ${ }^{2}$. Seeding in an untilled soil with a mulch layer requires specialised equipment, which is not always available (Giller et al, 2011). Also, the benefits of CA might not be immediate and only appear after some crop cycles, which might impede the adoption process. For example, it has been observed that during the first years of practicing CA, weed problems manifest, which might entail an additional cost for adequate application of herbicides or an increased amount of labour needed for manual or mechanical controls (Affholder et al, 2010; Oicha et al, 2010). Thirdly, a continued adoption requires farmers to persist with using the new technology. Farmers often revert back to their conventional methods once technical support, guidance or subsidies to apply the new technology have stopped, especially when results do not fulfill their high expectations (Davis, 2008). The active involvement of farmers themselves in the process of developing and diffusing a technology might substantially increase adoption rates (Erenstein et al, 2008).

In order to enhance $\mathrm{CA}$ adoption rates, a thorough understanding of the site-specific determinants and constraints in the adoption process is needed. Site-specificity is required as there are few, if any, universal variables that explain adoption in different contexts (Knowler and Bradshaw, 2007). Nevertheless, measuring adoption is not straightforward because of the complexity of the decisionmaking process and composite nature of contemporary agricultural technologies (Ervin and Ervin, 1982). In the early literature, adoption is measured as a simple dichotomous variable (adopter versus non-adopter). In recent years, more sophisticated models have been developed that account for the dynamic nature of the adoption process and intensity of technology adoption. Adoption of a technical innovation requires time as the farmer has to adapt to a new farming system. Different stages including awareness of the new agricultural technique, testing and continued use of the adopted practices - succeed each other and might be influenced by different factors (Pannell et al, 2006). The adoption decision of a farmer is not necessarily dichotomous, whether to adopt or not, but can also entail a choice about the level of effort or intensity of adoption (Saint-Macary et al, 2010). This can be measured as the percentage of area where the technology is applied, the number of adopted components of an innovation package or the number of cropping cycles in which a new technique is implemented. While the two first measures of intensity have been investigated (Mazvimavi and Twomlow, 2009; Byerlee and Hesse de Polanco, 1986), the latter has not. To understand why farmers adopt CA in only one cropping cycle per year while applying conventional methods in the other, represents a gap in the scientific literature.

The objective of this paper was to investigate the adoption of CA among medium-scale farmers in the Mexican Bajío. We used data from a survey among 305 farmers. We specifically differentiate between

\footnotetext{
${ }^{2}$ Depending on the site-specific conditions, there may be scope for partial residue retention, making livestock ownership more compatible with CA adoption (Govaerts et al, 2005; Verhulst et al, 2011).
} 
full and partial adoption of composite technology, and disentangle different steps in the adoption process, awareness and adoption, using Heckman selection models. This paper is structured as follows. First, the research area and data collection methods are presented. Secondly, three production systems are identified and their differences examined. Thirdly, some qualitative aspects of the process of CA adoption are described and the adoption process econometrically analysed. Finally, the conclusions and implications of the research are presented.

\section{Research area and data collection}

\section{Description of the Bajio}

The study area comprises the states of Guanajuato and Michoacán, located in the Bajío, an extensive highland plain in Central Mexico (Figure 1). The area ranges in elevation from approximately 1600 to 2000 meters above sea level, and deep, fertile Vertisols and Phaeozems are the most common soil types (Erenstein, 1999). There are two agricultural seasons;, (i) a wet season between May and October with rainfall of up to $160 \mathrm{~mm}$ per month when mainly maize (Zea mays) and sorghum (Sorghum bicolor) are grown in either rain-fed or irrigated systems, and (ii) a dry season between November and April with mean rainfall of $10 \mathrm{~mm}$ per month when mainly wheat (Triticum aestivum) and barley (Hordeum vulgare) are grown in irrigated systems (Erenstein, 1999). Access to irrigation in the area is controlled by government institutions through local irrigation districts and the majority of the fields are irrigated. The Bajío is one of the highest producing areas in Mexico, with average sorghum and maize yields typically reaching 8 to $12 \mathrm{t} / \mathrm{ha}$, and wheat and barley yields 5 to $7 \mathrm{t} / \mathrm{ha}$. The general profile of a cereal cultivating farmer in the Bajío is a medium-scale landholder with industrial farming machinery and good access to inputs (e.g. mineral fertilizers, commercial seeds, credit) and functional markets. The average cultivated area is about 16 ha per farm household. Main income is derived from crop cultivation and livestock production and sometimes supplemented with off-farm work, such as small side-businesses.

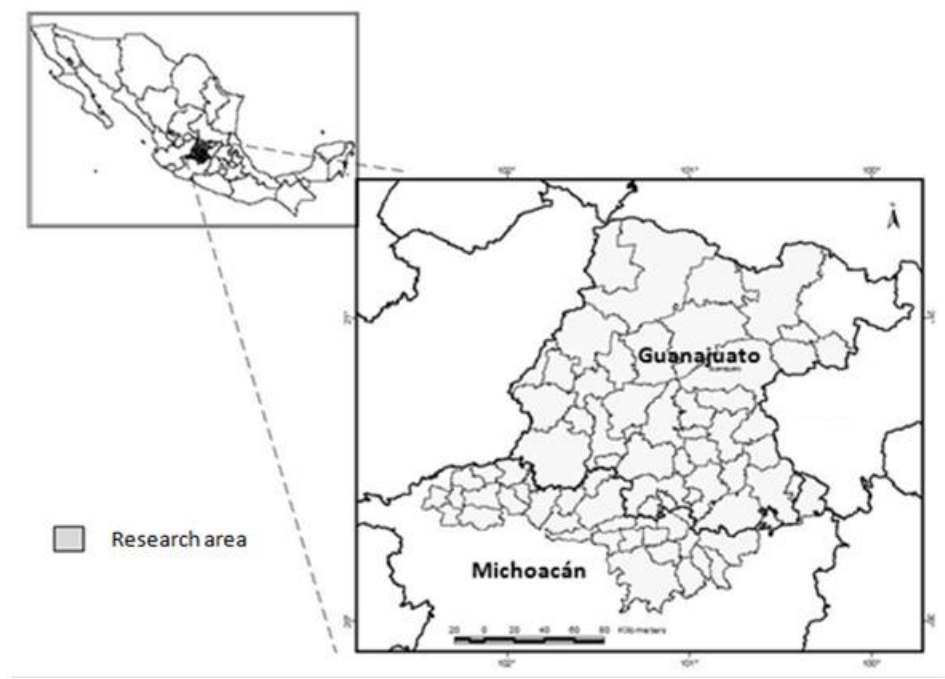

Figure 1 Map of the research area.

Sampling strategy and survey design

A farmer survey was conducted among 305 farmers in the two states of Guanajuato and Michoacán between August-September 2011. A two-stage stratified random sampling design was used. In a first stage, 30 counties were randomly selected in the two states, 16 in Michoacán and 14 in Guanajuato. In the second stage, farm-households in the selected counties were stratified according to whether or not they implement CA, and were sampled randomly within the strata with an oversampling of CA 
farmers. A quantitative and structured questionnaire, organized in different modules and sub-modules, was used for the survey. The respondent was the head of the household, in charge of farm-related decisions. The farmers were asked to choose their highest yielding parcel and plot characteristics were asked only for that parcel. This approach was used because farmers in the Bajío have different plots in different places. The survey yielded data on farmer and farm-household characteristics, farm financial/management characteristics, farm biophysical characteristics and institutional factors. Of the 305 observations, 282 were retained for analysis in view of missing values.

\section{CA and non-CA production systems}

\section{Classification of different production systems}

We identified three different production systems that capture different intensities of CA adoption, taking into account the three principles of CA and the seasons in which these are applied (Table 1). We distinguish two CA and one conventional production system: (i) full CA adoption (CA-full), defined as reduced tillage with residue retention and crop rotation in all cropping cycles; (ii) partial CA adoption (CA-part), defined as reduced tillage during one cycle, conventional tillage during the other cycle and any possible residue management (retention, burning ${ }^{3}$, baling, grazing or incorporation in the soil); and (iii) non-adoption or conventional agriculture (CT), defined as conventional tillage and no residue retention.

Table 1 Overview of the production systems.

\begin{tabular}{lll}
\hline Production system & Description & $\begin{array}{l}\text { Observations } \\
\mathrm{N}=282\end{array}$ \\
\hline $\begin{array}{l}\text { Conservation agriculture }- \\
\text { full adoption (CA-full) }\end{array}$ & Reduced tillage with residue retention and crop rotation \\
$\begin{array}{l}\text { Conservation agriculture }- \\
\text { partial adoption (CA-part) }\end{array}$ & $\begin{array}{l}\text { One cycle reduced tillage, other cycle conventional tillage, } \\
\text { any residue management }\end{array}$ & $118(41.8 \%)$ \\
$\begin{array}{l}\text { Conventional agriculture }- \\
\text { non-adoption (CT) }\end{array}$ & $95(33.7 \%)$ \\
\hline $\begin{array}{l}\text { Source: Authors' calculation from survey data. } \\
\text { Conal tillage and no residue retention }\end{array}$
\end{tabular}

\section{Differences across production systems}

In Table 2, we compare full, partial and non-adopters of CA in terms of farm, household and institutional characteristics. The results indicate that CA-full farmers are significantly younger than CT farmers, while CA-part farmers have significantly larger households. CA farmers, both CA-part and CA-full, have significantly higher levels of education than CT, and a higher probability of being in a male-headed household. Moreover, CA-part and CA-full farmers have significantly larger average farm sizes, 16.6 ha and 25.3 ha, respectively, than CT farmers (12.7 ha). Almost all CA-part farmers (92\%) and CA-full (83\%) have access to irrigation, whilst the equivalent for CT farmers is $40 \%$. Interestingly, CA-part farmers have a significantly higher likelihood of owning livestock and a lower likelihood of having off-farm earnings than CT farmers, while there is no difference between CA-full and CT farmers for these characteristics.

There are also important differences between farmers with respect to institutional factors. CA-full and CA-part farmers have better access to information, technical support and other services. More specifically, $69 \%$ of CA-full and 52\% of CA-part are advised by a technical assistant, who helps solving practical problems, compared to only $16 \%$ of CT farmers. CA farmers receive significantly more services from the organisations they are member of, including better access to credit, agricultural

\footnotetext{
${ }^{3}$ Burning of crop residues is illegal in Mexico, but the legislation of it is poorly enforced.
} 
insurance and subsidies. This descriptive analysis reveals that there are important differences in household, farm and institutional factors between CA and non-CA-farmers. In order to understand how important these factors are in farmers' adoption decisions, we need to further unravel the decision-making process.

\section{The process of CA adoption}

\section{Farmers' awareness of CA}

A first step in farmers' technology adoption process is gaining awareness and information on the technology. As a zero-till training centre is already active in the region (since the end of the 1980s) we expect to find high awareness rates ${ }^{4}$. However, in our sample, $10 \%$ of CA-part and 50\% of CT farmers had never heard of the term CA at the time of the survey. In the case of CA-part farmers, it is difficult to disentangle whether they really know about all of the three principles of CA, but prefer not to practice them all at the same time or throughout the year, or if they do not know about all of the three principles and think that their system is the 'right one'.

The channels through which information on CA is obtained differ across different production systems. CA-full farmers mostly get acquainted with CA by observing other farmers $(35 \%)$ or through technical assistance (33\%). CA-part and CT farmers who are aware of the CA technology mainly receive information on CA through other farmers (45\% and 30\%, respectively) and less through technical assistants (23\% and $8 \%$, respectively). These figures confirm that CA spreads in the region through pioneering farmers and followers. CA-full are likely pioneers who introduce the technique to other farmers after they adopted CA with support of a technical assistant. Neighbouring farmers observe CA practices on the fields of pioneers and gradually adopt different components of the technique.

\section{Farmers' perception about $C A$}

The main constraints for CA adoption according to our farmer sample are lack of information and technical assistance, lack of equipment, and risk aversion (Figure 2). More CT farmers (35\%) mention lack of equipment as a constraint than CA-full (26\%) and CA-part (22\%), but this difference is not significant. Lack of information and technical assistance is mentioned significantly more by CT farmers (44\%) than CA-full (28\%) and CA-part (20\%). On the contrary, being averse of risk taking is mentioned significantly more by CA-full (31\%) and CA-part (31\%) than by CT farmers (13\%).

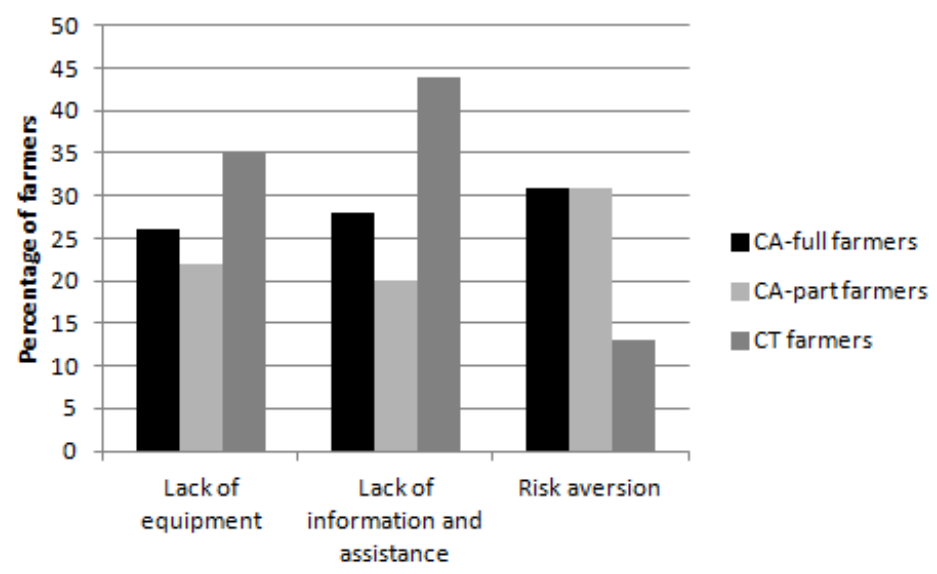

Figure 2 Farmers' perception of the constraints for CA adoption.

\footnotetext{
${ }^{4}$ The Villadiego training centre is located in Guanajuato and was set up by FIRA (Federal Trust Fund for Agriculture, Mexico).
} 
Table 2 Farm, household and institutional characteristics across different production systems.

\begin{tabular}{|c|c|c|c|c|}
\hline \multirow[t]{3}{*}{ Variables } & \multirow{3}{*}{$\begin{array}{l}\text { Description } \\
\text { (Measure unit) }\end{array}$} & \multicolumn{3}{|c|}{ Non CA-farmers } \\
\hline & & CT & CA-part & CA-full \\
\hline & & Mean (s.d.) & Mean (s.d.) & Mean (s.d.) \\
\hline \multicolumn{5}{|c|}{ Farmer and farm-household characteristics: } \\
\hline Age & Age of head of farm-household (years) & $56.68(14.11)$ & $54.38(13.47)$ & $52.75(10.99) * *$ \\
\hline Education & Dummy for starting higher education & $0.07(0.26)$ & $0.25(0.43) * * *$ & $0.23(0.43) * * *$ \\
\hline Household size & Number of persons living in the house & $4.94(3.17)$ & $4.46(2.10) *$ & $5.22(2.58)$ \\
\hline Gender & Dummy for gender of head of farm-household $(1=$ male; $0=$ female $)$ & $0.86(0.79)$ & $0.92(0.27) *$ & $0.96(0.21) * *$ \\
\hline \multicolumn{5}{|c|}{ Farm financial / management characteristics: } \\
\hline Off-farm income & Dummy for earning off-farm income & $0.30(0.46)$ & $0.22(0.41) *$ & $0.31(0.47)$ \\
\hline Livestock & Dummy for ownership of livestock & $0.50(0.46)$ & $0.62(0.49) * *$ & $0.47(0.50)$ \\
\hline Own land & Dummy for ownership of selected plot $(1=$ own; $0=$ rented $)$ & $0.80(0.40)$ & $0.83(0.38)$ & $0.80(0.41)$ \\
\hline \multicolumn{5}{|c|}{ Farm biophysical characteristics: } \\
\hline Total farm size & Total area cultivated in wet season (ha) & $12.67(15.92)$ & $16.57(21.09) *$ & $25.32(34.84) * * *$ \\
\hline Access to irrigation & Dummy for irrigating selected plot during dry season & $0.40(0.49)$ & $0.92(0.28) * * *$ & $0.83(0.38) * * *$ \\
\hline Soil texture & Dummy for soil texture of selected plot $(1=$ clay; $0=$ other $)$ & $0.83(0.38)$ & $0.82(0.39)$ & $0.81(0.39)$ \\
\hline Vertic properties & Dummy for presence of vertic properties in selected plot & $0.74(0.44)$ & $0.74(0.44)$ & $0.72(0.45)$ \\
\hline \multicolumn{5}{|l|}{ Institutional factors: } \\
\hline Technical assistance & Dummy for consulting a technical assistant & $0.16(0.37)$ & $0.52(0.50) * * *$ & $0.69(0.47) * * *$ \\
\hline Organizational services & Number of services farmer receives from agricultural organizations & $0.95(1.69)$ & $1.18(2.19) * * *$ & $2.29(2.38) * * *$ \\
\hline Information & Use of different information canals $(\%)$ & $0.37(0.22)$ & $0.47(0.22) * * *$ & $0.50(0.16) * * *$ \\
\hline
\end{tabular}

CA-full are farmers who fully adopt CA, CA-part farmers partially adopt CA and CT are conventional farmers who do not adopt CA. Characteristics of CA-part and CA-full farmers are compared to those of CT farmers using $\mathrm{t}$-tests. Significant differences are indicated with $* \mathrm{p}<0.1, * * \mathrm{p}<0.05$ or $* * * \mathrm{p}<$ 0.01 .

The variable 'Information' is calculated as the sum of the weights $(0=$ never used, $1=$ sometimes used, $2=$ frequently used) of the different information canals (television, radio, internet, cell phones, printed media, technical assistance and neighbours), divided by 14 (the maximum value of the total sum of information). 
The main benefits experienced by CA-part and CA-full farmers are: reduced costs for machinery and diesel, reduced labour requirements, and improvement of soil properties, such as the water retention capacity (Figure 3). Significantly more CA-full (80\%) mention the advantage of improved soil and water holding properties than CA-part (70\%). On one hand, this might indicate that CA-full attach a higher importance to environmental benefits, while CA-part are more interested in cost and labour savings. This is in line with CA-full having a more long term perspective than CA-part, which is plausible given that CA-full farmers have larger farm sizes. On the other hand, it might also indicate that full adoption of all components of CA in all seasons is needed before substantial improvements in soil properties materialize, as suggested by Hobbs et al (2008). Very few farmers mention higher yields as a benefit of CA, as CA does not necessarily result in higher yields compared to conventional practices in irrigated conditions (Verhulst et al, 2011).

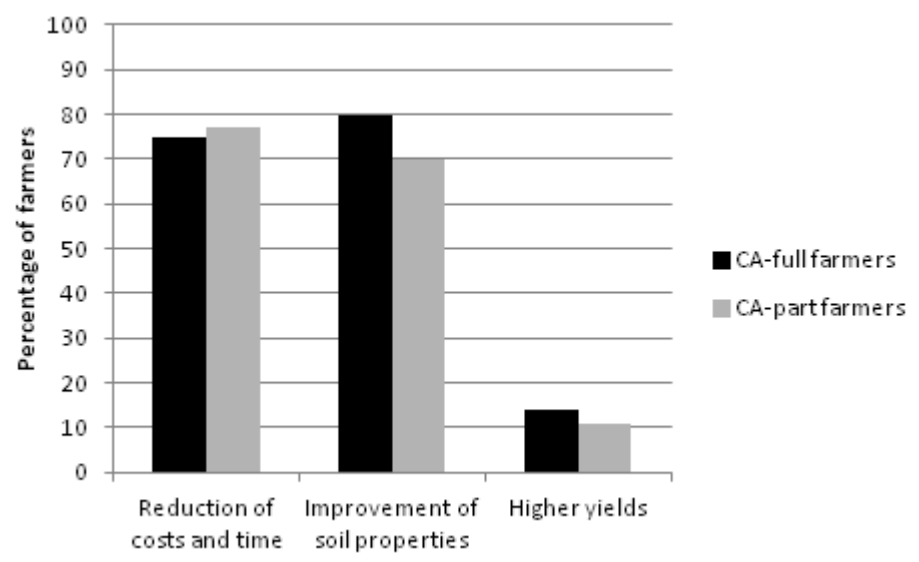

Figure 3 Farmers' perception of the benefits of CA adoption.

Almost half the CA farmers did not experience any difficulties while implementing CA. The main difficulties mentioned include the need for specialized machinery, weed problems and water supply problems (both shortage and abundance). The latter problem might occur when heavy clay soils are inherently poorly drained, as is the case in most soils in the Bajío. Other minor difficulties include the need for terrain levelling, the knowledge intensity of the technology and soil compaction. A minority of farmers experience problems with their neighbours, including fire from residue burning passing over from one field to another, cattle entering the CA fields to graze, and the conviction that farmers who do not till the soil are lazy. However, most neighbours changed their mind after observing the good results of CA. In an overall evaluation, both CA-full and CA-part farmers think the benefits compensate for the difficulties and are willing to increase their cultivated area under CA.

\section{Econometric analysis of adoption}

From the descriptive statistics, it is clear that there are important differences in various characteristics between the three production systems. This section includes a causal analysis of the determinants of CA adoption, taking into account the distinction between full and partial adoption technology uptake and the different steps in the adoption process, awareness and adoption.

\section{Estimation strategy}

Since the outcome of an adoption decision is dichotomous, probit models are used to analyse awareness and adoption of CA. However, as not every farmer in the Bajío is aware of CA, the investigation of adoption determinants may lead to biased estimates when aware and unaware farmers differ in their likelihood to adopt the technology (Diagne and Demont, 2007). This is likely the case if knowledge acquisition is part of the farmers' adoption decision and therefore endogenous or if, for efficiency reasons, agricultural extension especially targets innovative farmers (Saint-Macary et al, 2010). This calls for the use of a selection bias 
correction model. A bivariate probit model with sample selection (Heckprobit model) is used to jointly estimate the probability of knowing and adopting CA and to control for selection bias. It consists of a selection equation (the awareness stage) and the outcome equation (the adoption stage) (Wooldridge, 2009).

$$
\begin{array}{rlrlrl}
y_{1} & =1 & \text { if } \quad[\alpha X+\beta Z+\varepsilon>0] & & & \text { (awareness stage) } \\
y_{2} & =1 \quad \text { if } \quad[\gamma X+u>0] \quad \text { and } \quad y_{1}=1 & & \text { (adoption stage) } \\
& =0, & \text { otherwise } & & &
\end{array}
$$

Awareness is the first dependent variable $\left(\mathrm{y}_{1}\right)$ indicating whether the farmer knows CA (value $=1$ ) or not (value $=0$ ). Two alternative variables are used for the second dependent variable $\left(\mathrm{y}_{2}\right)$ in order to distinguish between full and partial adoption. In a first alternative, we define $\mathrm{y}_{2}$ as general adoption, comprising both CA-full and CA-part adopters. Its value is 1 if the farmer adopts at least one component of CA (zero/minimal tillage or residue retention) in at least one cropping cycle per year, while it is 0 if the farmer never adopts any component of CA. In a second alternative, the dependent variable is defined as full adoption, whether the farmer jointly adopts the three components of $\mathrm{CA}$, in each cropping cycle (value $=1$ ) or not $($ value $=0$ ).

The independent variables ( $\mathrm{X}$ and $\mathrm{Z}$ ) used for the econometric analysis of adoption are described in Table 2. Farmer and farm-household characteristics (age, education, farm-household size and gender), farm financial/management characteristics (off-farm income, livestock and type of land tenure), farm biophysical characteristics (total farm size, access to irrigation and soil properties) and institutional factors (technical assistance, organizational services and information) are included in the model. A quadratic term of age is added to take into account the effect of this variable, as both young and old farmers might have (dis)incentives to adopt CA. Younger farmers who have longer planning horizons are assumed to be more willing to invest in new agricultural technologies, while older farmers are more experienced, which could also positively influence the adoption decision. To take into account location effects, a dummy variable for living in Michoacán (value $=1$ ) or living in Guanajuato (value $=0$ ) is included. The variable 'Information' is chosen as the selection variable $(\mathrm{Z})$ in the Heckprobit model, as general access to information is highly correlated with awareness of new agricultural technologies, but less with the actual adoption. Because of the non-linear nature of the model, coefficient estimates cannot be directly interpreted. Therefore, average marginal effects (AME) are calculated.

\section{Results and discussion}

In Table 3, the results of the first stage of the Heckprobit regression on awareness of CA are presented. The results indicate that institutional factors, including technical assistance, organizational services and access to information, have a highly significant and positive effect on the probability that farmers are aware of CA. This is consistent with previous findings in the literature on the importance of institutional factors in the diffusion of agricultural innovations (Wollni et al, 2010). Also education and access to irrigation both have a significant and positive effect on the likelihood of awareness. An explanation might be that better educated and better-off farmers with access to irrigation more actively seek information. Being a land-owner decreases a farmers' likelihood to be aware of CA while total farm size does not have a significant effect. A possible explanation is that land-owners have less contact with other farmers than farmers who rent land and are therefore less exposed to information exchange between farmers. Farmers in Michoacán are significantly less aware of CA than those in Guanajuato, which relates to the fact that CA was first introduced in Guanajuato. 
Table 3 Results of Heckprobit model for awareness (first stage).

\begin{tabular}{lll}
\hline Variables & Average marginal effects \\
\hline Age & 0.0056 \\
Age $^{2}$ & -0.0001 \\
Education & $0.1334 \quad *$ \\
HH size & 0.0023 & \\
Gender & 0.0363 & \\
Off-farm income & -0.0378 & \\
Livestock & 0.0556 & \\
Own land & $-0.1731 \quad * * *$ \\
Total farm size & $0.0008 \quad$ \\
Irrigated & $0.1363 \quad * * *$ \\
Soil type & -0.0042 & \\
Vertic properties & -0.0528 & \\
Technical assistance & $0.2313 \quad * * *$ \\
Functionality of organization & $0.0402 \quad * *$ \\
Information & $0.3332 \quad * * *$ \\
Michoacán & $-0.1175 \quad * * *$ \\
\hline N $=280$ & Wald $\mathrm{Chi}^{2}=23.46 *$ \\
\hline
\end{tabular}

Z-statistics are significant at $0.1(*), 0.05(* *)$ or $0.01(* *)$ significance level.

In Table 4, the results of the single-stage probit on adoption of CA and the second stage of the Heckprobit selection model are presented. The first two columns report the results for general adoption, including full and partial adoption, while the last two columns report the results on full adoption only. The correlation between the error terms of the awareness and adoption stage $(\rho)$ is significant for both Heckprobit models. This indicates a problem of selection bias, which justifies the use of Heckprobit selection models for both general and full CA adoption. The Wald $\mathrm{Chi}^{2}$ test is significant for both probit and Heckprobit models, so the null hypothesis stating that all variables can be jointly excluded can be rejected, confirming that the models fit well.

First, in all models, we observe a positive but decreasing effect of age, indicating that middle-aged farmers are most likely to adopt CA. The turning point after which the effect of age becomes negative is 55 for general adoption and 54 for full adoption. Older age is hence a more important constraint for full CA adoption than for partial adoption. Secondly, the estimated marginal effects for education and technical assistance are positive and significant in the single probit models (education only in the general adoption model) but not in the Heckprobit selection models. Also in the first stage probit regression on awareness these variables were found to have a positive effect (Table 3). This indicates that education and technical assistance are important for creating awareness but once farmers are aware, they do not further determine farmers' adoption decisions. This finding justifies our approach of disentangling the different steps in the adoption process and the use of selection models to correct for selection bias caused by non-awareness for a non-random part of the population. Thirdly, when correcting for selection bias in Heckprobit models, land ownership has a positive and significant effect on general CA adoption (and a marginally significant effect on full adoption). Given the significantly negative effect on awareness (Table 3), this means that land ownership decreases awareness of CA but increases the adoption of CA components in at least one season once farmers are aware. The effect is quite large; land ownership increases the likelihood of adoption with about 10 percentage points. The observed effect of land ownership is likely related to the fact that an important part of the benefits of CA are not immediate and only materialize after some years. Owning ones land gives farmers more certainty of reaping the future benefits of their current investments in CA. 
Fourth, access to irrigation positively affects general CA adoption, but has a negative effect on full adoption. This seemingly contradicting effect might be explained by the fact that it is easier to fully implement CA in rain-fed farming systems, as crops are only grown during one season per year. Nevertheless, the share of CA-part and CA-full farmers who have access to irrigation (92\% and $83 \%$, respectively) remains high compared to CT farmers (40\%). Finally, an interesting observation is the significantly negative effect of livestock ownership on full CA adoption (but not on general adoption). Ownership of livestock decreases the probability of implementing all CA components in all cropping cycles with 13 percentage points, but does not affect the likelihood of implementing some components in some cropping cycles. Farmers who own livestock likely depend on their residues as fodder and are therefore less inclined to retain the residues on the fields. Summer residues are more often baled than winter residues, because extra fodder is needed especially in drier winter periods, creating scope for CA practices with residue retention in the summer season only. In addition, farmers who own livestock tend to cultivate more sorghum, which is used as fodder, and less maize. Residues of sorghum are more difficult to manage for direct seeding than maize residues, because they are harder to cut, resulting in an extra disincentive for farmers with livestock to implement CA in the winter cycle.

Table 4 Results of probit and Heckprobit model for general and full adoption (second stage).

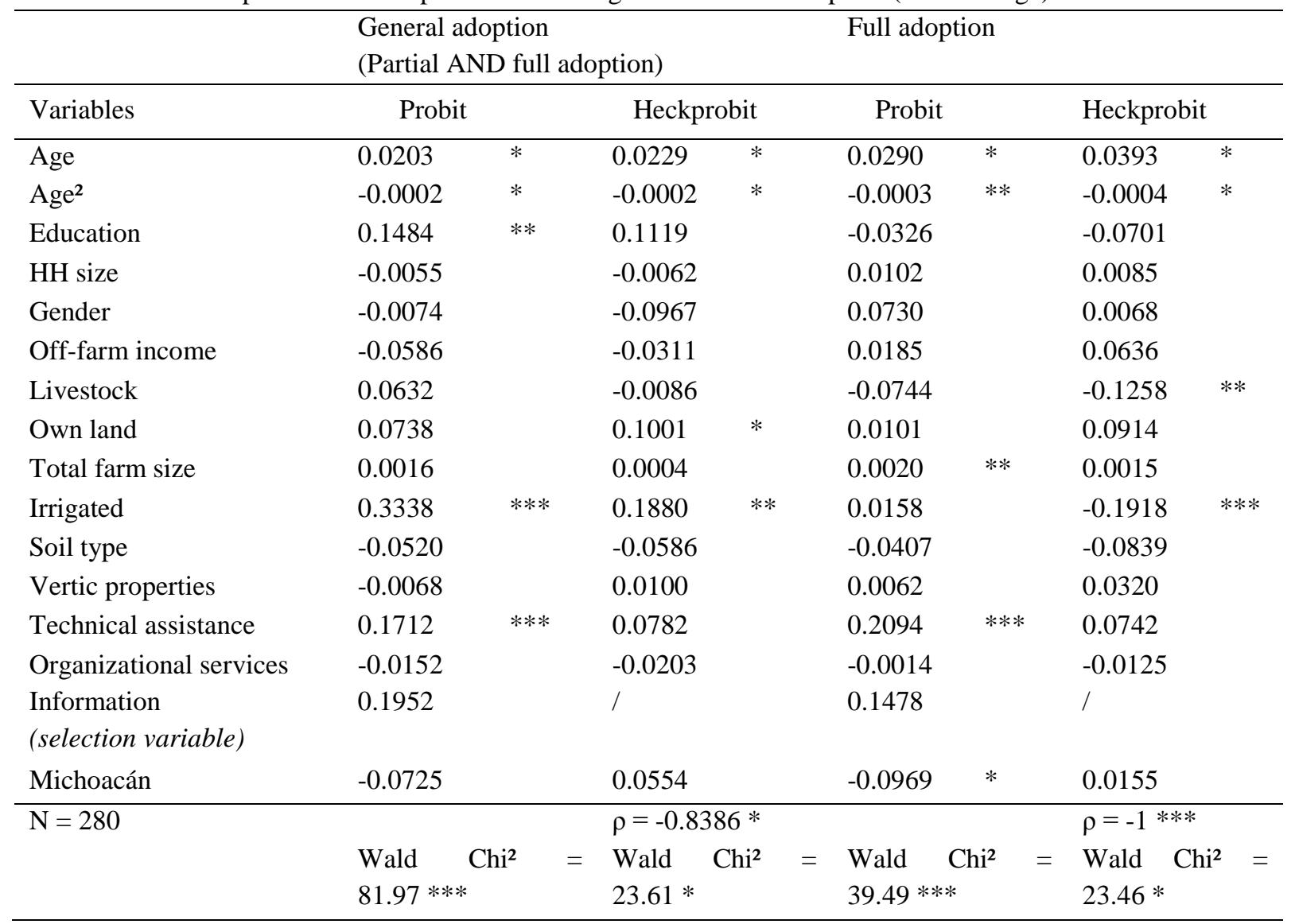

Z-statistics are significant at $0.1(*), 0.05(* *)$ or $0.01(* *)$ significance level.

\section{Conclusions}

Our analysis of the adoption process of CA among farmers in the Mexican Bajío reveals that there are differences in the intensity of adoption, with some farmers adopting all components of CA in both cropping seasons while others adopting only some components in one cropping cycle. In a causal analysis we demonstrate that there are important differences in how institutional factors and farm and household characteristics influence the different steps in the adoption decision process. We demonstrate that the use of two-stage selection models allows to disentangle these different steps in farmers' decision-making process 
and to more accurately estimate effects. Our results indicate that farmers' education and access to technical assistance - factors that are often considered as crucial in determining innovation adoption - are only important in affecting awareness about the technology, but do not influence adoption itself once awareness is controlled for. This raises questions on whether the efforts of extension on CA should lay in creating a wider outreach or in intensifying the assistance to farmers. Further, we find that adoption of CA is not determined by farm size or access to off-farm income and hence adoption is not biased towards relatively wealthier farmers. This result might be related to the specific case-study background and the specific type of technology. While capital constraints are usually found to be important for technology adoption among farmers in developing countries, medium-scale farmers in the Mexican Bajío might be less capital constrained and CA technology less capital intensive, or even capital-saving. Nevertheless, even among medium-scale and less capital constrained farmers, land rights are important for technology adoption. A main constraint for full but not for partial CA adoption is livestock ownership which complicates residue retention on the field, as it is baled for fodder. This calls for further research on the environmental and economic outcomes of CA under varying levels of residue retention in order to make CA adoption more compatible with livestock ownership.

\section{Acknowledgement}

The authors would like to thank the surveyors and farmers who participated in the survey. Special thanks go to Luis Vargas Rojas for his valuable contribution to the research. The research was funded by 'Desarrollo sustentable con el productor', part of 'Modernización Sustentable de la Agricultura Tradicional', supported by SAGARPA, through the International Maize and Wheat Improvement Center (CIMMYT, Int.). It was conducted under the CGIAR Research Program on Climate Change Agriculture and Food Security (CCAFS).

\section{References}

Affholder, F., Jourdain, D., Quang, D.D., Tuong, T.P., Morize, M., and Ricome, A. (2010), 'Constraints to farmers' adoption of direct-seeding mulch-based cropping systems: A farm scale modeling approach applied to the mountainous slopes of Vietnam', Agricultural Systems, Vol 103, pp 51-62.

Byerlee, D., and Hesse de Polanco, E. (1986), 'Farmers' stepwise adoption of technological packages: evidence from the Mexican Altiplano', American Journal of Agricultural Economics, Vol 68, pp 519-527.

Cavalieri, K.M., da Silva, A., Tormena, C.A., Leão, T.P., Dexter, A.R., and Hakansson, I. (2009), 'Long-term effects of no-tillage on dynamic soil physical properties in a Rhodic Ferrasol in Paraná, Brazil', Soil and Tillage Research, Vol 103, pp 158-164.

Diagne, A., and Demont, M. (2007), 'Taking a new look at empirical models of adoption: average treatment effect estimation of adoption rates and their determinants', Agricultural Economics, Vol 37, pp 201-210.

Davis, K.E. (2008), 'Extension in Sub-Saharan Africa: Overview and Assessment of Past and Current Models, and Future Prospects', Journal of International Agricultural and Extension of Education, Vol 15, pp 15-28.

Derpsch, R., Friedrich, T., Kassam, A., and Hongwen, L. (2010), 'Current status of adoption of no-till farming in the world and some of its main benefits', International Journal of Agricultural and Biological Engineering, Vol 3, No $1, \mathrm{pp} 1-26$.

Dumanski, J., Peiretti, R., Benetis, J., McGarry, D., and Pieri, C. (2006), 'The paradigm of conservation tillage', Proceedings of World Association of Soil and Water Conservation, Vol 1, pp 58-64.

Erenstein, O. (1999), 'The Economics of Soil Conservation in Developing Countries: The Case of Crop Residue Mulching', Ph.D. thesis, Wageningen University, the Netherlands, $301 \mathrm{p}$.

Erenstein, O., Sayre, K., Wall, P., Dixon, J., and Hellin, J. (2008), 'Adapting no-tillage agriculture to the conditions of smallholder maize and wheat farmers in the tropics and sub-tropics', In: Goddard, T., Zoebisch, M., Gan, Y., Ellis, W., Watson, A., and Sombatpanit, S. (Eds.), No-till Farming Systems. Special Publication 3. World Association of Soil and Water Conservation (WASWC), Bangkok, 253-278.

Ervin, C.A., and Ervin, D.E. (1982), 'Factors affecting the use of soil conservation practices: Hypotheses, Evidence and Policy Implications', Land Economics, Vol 58, pp 277-292. 
Fabrizzi, K.P., García, F.O., Costa, J.L., and Picone, L.I. (2005), 'Soil water dynamics, physical properties and corn and wheat responses to minimum and no-tillage systems in the southern Pampas of Argentina', Soil and Tillage Research, Vol 81, pp 57-69.

Giller, K., Witter, E., Corbeels, M., and Tittonell, P. (2009), 'Conservation agriculture and smallholder farming in Africa: The heretics' view', Field Crops Research, Vol 114, pp 23-34.

Giller, K.E., Corbeels, M., Nyamangara, J., Triomphe, B., Affholder, F., Scopel, E., and Tittonell, P. (2011), 'A research agenda to explore the role of conservation agriculture in African smallholder farming systems', Field Crops Research, Vol 124, pp 468-472.

Govaerts, B., Sayre, K. D., and Deckers, J. (2005), 'Stable high yields with zero tillage and permanent bed planting?', Field Crops Research, Vol 94, pp 33-42.

Hobbs, P. R., Sayre, K. D., and Gupta, R. (2008), 'The role of conservation agriculture in sustainable agriculture', Philosophical Transactions of the Royal Society, Vol 363, pp 543-555.

Knowler, D., and Bradshaw, B. (2007), 'Farmers' adoption of conservation agriculture: a review and synthesis of recent research', Food Policy, Vol 32, pp 25-48.

Lahmar, R. (2010), 'Adoption of conservation agriculture in Europe: Lessons of the KASSA project', Land Use Policy, Vol 27, pp 4-10.

Lestrelin, G., Nanthavong, K., Jobard, E., Keophoxay, A., Lienhard, P., Khambanseuang, C., and Castella, J. (2012). 'To till or not to till? The diffusion of conservation agriculture in Xieng Khouang province, Lao PDR. Opportunities and constraints', Outlook on agriculture, Vol 41, No 1, pp 41-49.

Malhi, S.S., Lemke, R., Wang, Z.H., Chhabra, and Baldev S. (2006), 'Tillage, nitrogen and crop residue effects on crop yield, nutrient uptake, soil quality, and greenhouse gas emissions', Soil and Tillage Research, Vol 90, pp 171-183.

Marongwe, L. S., Kwazira, K., Jenrich, M., Thierfelder, C., Kassam, A., and Friedrich, T. (2011), 'An African success: the case of conservation agriculture in Zimbabwe', International Journal of Agricultural Sustainability, Vol 9, No 1, pp 153-161.

Mazvimavi, K., and Twomlow, S. (2009), 'Socioeconomic and institutional factors influencing adoption of conservation farming by vulnerable households in Zimbabwe', Agricultural Systems, Vol 101, pp 20-29.

Oicha, T., Cornelis, W., Verplancke, H., Nyssen, J., Govaerts, B., Mintesinot B., Mitiku, H., and Deckers, J. (2010), 'Short-term effects of conservation agriculture on Vertisols under tef (Eragrostis tef (Zucc.) Trotter) in the northern Ethiopian highlands', Soil and Tillage Research, Vol 106, pp 294-302.

Pannell, D.J., Marshall, G.R., Barr, N., Curtis, A., Vanclay, F., and Wilkinson, R. (2006), 'Understanding and promoting adoption of conservation practices by rural landholders', Australian Journal of Experimental Agriculture, Vol 46, pp 1407-1424.

Saint-Macary, C., Keil, A., Zeller, M., Heidhues, F., and Dung, P.T.M. (2010), 'Land titling policy and soil conservation in the northern uplands of Vietnam', Land Use Policy, Vol 27, pp 617-627.

Sayre, K., and Hobbs, P.R. (2003), 'Raised bed system of cultivation for irrigated production conditions', In: Lal, R., Hobbs, P., Uphoff, N., Hansen, D.O. (Eds.), Sustainable Agriculture and the Rice-wheat System. Ohio State University, Columbus, OH, USA, 337-355.

Tesfaye, A., Cornelis, W., Nyssen, J., Govaerts, B., Bauer, H., Tewodros, G., Tigist, O., Raes, D., Sayre, K., Mitiku, H., and Deckers, S. (2011), 'Effects of conservation agriculture on runoff, soil loss and crop yield under rain fed conditions in Tigray, Northern Ethiopia', Soil Use and Management, Vol 27, No 3, pp 404-414.

Verhulst, N., Govaerts, B., Verachtert, E., Castellanos-Navarrete, A., Mezzalama, M., Wall, P., Deckers, J., and Sayre, K.D. (2010), 'Conservation Agriculture, Improving Soil Quality for Sustainable Production Systems?' In: Lal, R., Stewart, B.A. (Eds.), Advances in Soil Science: Food Security and Soil Quality. CRC Press, Boca Raton, FL, USA, 137-208.

Verhulst, N., Sayre, K.D., Vargas, M., Crossa, J., Deckers, J., Raes, D., Govaerts, B. (2011). Wheat yield and tillagestraw management system $\times$ year interaction explained by climatic co-variables for an irrigated bed planting system in northwestern Mexico. Field Crops Research, Vol 124, pp 347-356.

Wollni, M., Lee, D.R., and Thies, J.E. (2010), 'Conservation agriculture, organic marketing, and collective action in the Honduran hillsides', Agricultural Economics, Vol 41, pp 373-384.

Wooldridge, J.M. (2003), 'Introductory Econometrics: A Modern Approach, second edition', South-Western College Publishing, Cincinatti, OH. 818 p. 